Received: July 26, 2020

Accepted: September 10, 2020

\section{Correspondence}

Raffaele Pezzella

Department of Life Health \& Environmental Sciences, University of L'Aquila, Unit of Orthopaedics and Traumatology, piazzale S. Tommasi 1, 67100

Coppito (AQ), Italy

E-mail: raffaelepezzella008@gmail.com

Conflict of interest

The Authors declare no conflict of interest

How to cite this article: Pezzella R, Toro G, Improda $\mathrm{G}$, The challenge of total knee arthroplasty periprosthetic fracture: a comprehensive review. Lo Scalpello Journal 2020;34:104-11. https:// doi.org/10.36149/0390-5276-169

(C) Ortopedici Traumatologi Ospedalieri d'Italia (O.T.O.D.I.) 2020

\section{(c) (i) $९$}

This is an open access article distributed in accordance with the CC-BY-NC-ND (Creative Commons Attribution-NonCommercial-NoDerivatives 4.0 International) license. The article can be used by giving appropriate credit and mentioning the license, but only for non-commercial purposes and only in the original version. For further information: https://creativecommons.org/licenses/by-nc-nd/4.0/deed.en

\title{
The challenge of total knee arthroplasty periprosthetic fracture: a comprehensive review
}

\author{
Raffaele Pezzella', Giuseppe Toro², Giuseppe Improda ${ }^{3}$, \\ Mariano Giuseppe Di Salvatore ${ }^{4}$, Antonio Tramontano ${ }^{4}$, \\ Adriano Braile ${ }^{2}$, Annalisa De Cicco ${ }^{2}$, Antonio Toro ${ }^{5}$, Antonio \\ Medici $^{4}$, Achille Pellegrino ${ }^{3}$ \\ ${ }^{1}$ Department of Life Health \& Environmental Sciences, University of L'Aquila, Unit of \\ Orthopaedics and Traumatology, L'Aquila, Italy; ${ }^{2}$ Department of Medical and Surgical \\ Specialties and Dentistry, University of Campania "Luigi Vanvitelli", Naples, Italy; ${ }^{3}$ Unit \\ of Orthopaedics and Traumatology, "S. Giuseppe Moscati" Hospital, Aversa, Italy; ${ }^{4}$ Unit \\ of Orthopaedics and Traumatology, AORN "S. Giuseppe Moscati", Avellino, Italy; ${ }^{5}$ Unit \\ of Orthopaedics and Traumatology, Villa Malta Hospital, Sarno, Italy
}

\begin{abstract}
SUMMARY
Total knee arthroplasty (TKA) is a common procedure in orthopeadic surgery. It has been estimated that the incidence of periprosthetic fractures after TKA ranged between 0.3 to $2.5 \%$, but increases to $38 \%$ when considering revision TKA.

Patient-related risk factors for TKA periprosthetic fracture (TKAPF) include osteoporosis, age, female gender, revision arthroplasty and osteolysis. The choice of the most appropriate fixation device of TKAPF is a matter of debate, considering that locking plates and retrograde intramedullary are both associated with good outcomes in terms of fracture union and joint function.

In case of prosthetic component instability, severe comminution or metaphyseal extension of the fracture that precludes fixation, failure of previous treatments, and severe malalignment of the TKA, revision TKA (RTKA) should be considered. Severe bone loss is another issue of concern, that might be addressed using both megaprosthesis or allograft-prosthesis composite. Considering the variability of the clinical scenario of TKAPF, a comprehensive approach based on both fracture fixation and/or revision arthroplashty is needed.
\end{abstract}

Key words: periprosthetic fracture, total knee arthroplasty, revision, retrograde nail, plate, fixation

\section{Introduction}

Total knee arthroplasty (TKA) is a common procedure performed in the elderly; considering the long life expectancy, and the age-related increasing of both osteoporosis and sarcopenia, the incidence of periprosthetic fractures around the knee is constantly growing up ${ }^{1}$.

It has been estimated that the incidence of periprosthetic fractures after TKA ranges between 0.3 to $2.5 \%{ }^{2-4}$, but increase to $38 \%$ when considering revision TKA ${ }^{4}$. The majority of these fractures occur between 2 to 4 years postoperatively and more often affect the distal femur $(2 \%)$, compared to the proximal tibia $(0.3-0.5 \%)^{4}$. An 
important factor that acts in this field is the implant design ${ }^{5}$. The intraoperative rate of periprosthetic TKA fractures is $4 \%{ }^{6}$, but it is probably underreported.

Several risk factors had been identidied including both patientand surgical-related factors.

Patient-related risk factors for TKA periprosthetic fracture (TKAPF) are osteoporosis, age, female sex, revision and osteolysis ${ }^{7}$. On the other hand, surgical-related risk factors are use of long tibial stems, cementless press-fit fixation, malalignment of the tibial component, tibial tuberosity osteotomy, and osseous defects in revision arthroplasty ${ }^{5,8,9}$.

TKAPF in the elderly should be considered a life-threatening condition, as underlined in studies reporting a one-year mortality between 11 to $44.8 \%{ }^{10,11}$. Therefore, the objectivies of treatment should be similar to other fragility fractures: early mobilization and weight bearing in order to reduce the patient's morbidity and mortality ${ }^{12}$.

The treatment of TKAPF presents a relevant complication rate. A review of 415 cases reported a nonunion rate of $9 \%$, fixation failure in $4 \%$, an infection rate of $3 \%$, and revision surgery in $13 \%{ }^{12}$

The choice of the most appropriate fixation device of TKAPF is a matter of debate, considering that locking plates and retrograde intramedullary are both associated with good outcomes in terms of fracture union and joint function ${ }^{13}$.

Moreover, considering the extreme variability of fracture pattern, a comprehensive approach to each case may be advisable. In order to give a practical guide to the orthopedic surgeon in the treatment decision making of TKAPF we conducted a comprehensive review of the last 10 years on the treatment of this challenging condition.

\section{Etiology and risk factors}

TKAPF occurs most frequently in the supracondylar area of the femur ${ }^{11,14}$, with a reported incidence of $0.3-2.5 \%$ after 2 to 4 years after surgery ${ }^{15-17}$. Generally, these fractures are commonly observed around a well-fixed femoral component, after a low-energy trauma caused by torsional or compression forces ${ }^{14,18}$.

Risk factors for the occurrence of a supracondylar TKAPF include prolonged steroid use, osteoporosis, rheumatoid arthritis, advanced age, female gender, neurologic disorders, anterior femoral notching, elastic modulus mismatch between the implant and the femoral cortex, rotationally inged implants, osteolysis, delayed bone remodeling due to vascular compromise at the surgical site, knee joint ankylosis, and previous revision TKA ${ }^{14,15,19}$.

Anterior femoral notching refers to a defect of the anterior femoral cortex caused by excessive resection of the anterior femur during surgery. Several studies demonstrated that anterior femoral notching is closely associated with supracondylar TKAPF as it occurred in $10-46 \%$ of notched femurs ${ }^{19,20}$. The mechanism through which anterior notching leads to TKAPF was studied by Culp et al. ${ }^{19}$. The authors reported that a $3 \mathrm{~mm}$ anterior cortical notch results in a $30 \%$ reduction of torsional bone strength, thus increasing the risk of femoral fracture ${ }^{19}$. Interestengly, femoral fractures may also occur after navigation-assisted TKA at pinhole sites ${ }^{20}$.

The prevalence of TKAPF around the tibial implant is relatively low $(0.4-1.7 \%)^{21,22}$.

TKAPF can occur throughout the entire procedure: from the bone cuts to the placement of the polyethylene insert ${ }^{6,23}$.

However, TKAPF can be observed most commonly during joint exposure and bone cutting (39\%) and trial components implantation $(33 \%)^{6}$. A phase at high risk is the removal of an implanted prosthesis during revision surgery ${ }^{6,23}$. Some studies associated the preoperative neutral/valgus alignment with tibial fractures and tibial shaft fractures to tibial tubercle osteotomy ${ }^{23}$.

Most postoperative fractures result from acute trauma, but stress fractures may also be observed ${ }^{21}$.

In contrast to TKAPF around the femoral compontent, tibial fractures are often associated with component loosening or instability, as well as component malalignment, malpositioning, and joint instability ${ }^{7}$. Rand et al. observed a malalignment of the knee joint or a tibial component malpositioning in all patients with stress fractures of the tibia following TKA ${ }^{21}$. Lotke and Ecker ${ }^{24}$ suggested that varus fixation of the tibial component was associated with medial plateau fracture. During TKA, care should be taken to not lateralise the tibial component excessively in patients with a history of high tibial osteotomy in order to avoid contact between the tibial stem and the lateral cortex of the tibia during implantation ${ }^{25}$.

\section{Diagnosis of TKAPF}

If a fracture is suspected, long-leg radiography should be performed for confirmation. If pain is present without evidence of an obvious fracture or prosthesis loosening, blood tests, and joint aspiration should be performed to rule out infection ${ }^{26}$.

Standard anteroposterior and lateral views are the basis of fracture analysis and classification. Before classifying the fracture, the stability of the prosthesis should be assessed evaluating the patient's history before the trauma (a history of pain around the prosthesis may indicate previous loosening) and conventional X-ray ${ }^{27}$.

Typical signs of loosening, like shield displacement from the distal femur or separation of cement, might be detected. In ambiguous cases, a CT-scan may help find signs of loosening, particularly around the femoral component ${ }^{27}$.

However, to diagnose a loosing implant can be extremely hard, particularly in case of TKAPF, a condition in which prosthetic loosening might be partial. Therefore, the surgeon should be prepared to perform a revision arthroplasty, even though an osteosynthesis was initially planned. 
Sometimes, septic loosening may precede the TKAPF. Therefore, laboratory tests (eg. ESR, CRP) and analysis of the intraarticular fluid for white blood cells and bacteria is recommended in patients with suspicion of infection ${ }^{26}$.

\section{Classification}

Several classification systems have been proposed for both femoral and tibial TKAPF.

One of the mostly used is that proposed by Rorabeck and Taylor for femoral fracture ${ }^{17}$ in 1998 . This classification considers implant fixation status and fracture displacement.

Su et al. ${ }^{2}$, instead, suggested a classification system based on the relationship of the fracture line with the femoral component.

More recently, Kim et al. ${ }^{27}$ proposed a classification based on periprosthetic bone stock, prosthesis stability, and reducibility of the fracture.

Regarding the tibial periprosthetic fracture the most commonly used classification system was the one suggested by Felix et al. ${ }^{22}$. According to these authors, periprosthetic fractures around the tibia can be categorized into four types (I-IV) and three subtypes (A, B, C) depending on the anatomical location of the fracture and the tibial component fixation. See Table I for further details.

\section{Treatment}

The treatment of TKAPF should promote fracture union and joint function recovery. Acceptable alignments after fracture reduction are $<5 \mathrm{~mm}$ translation, $<5^{\circ}-10^{\circ}$ angulation, $<10^{\circ}$ rotational deformity, and $<1 \mathrm{~cm}$ femoral shortening ${ }^{28}$. In case of severe fracture displacement, comminution, or intercondylar extension, it can be difficult to obtain satisfying functional outcomes.

In addition, the action of adductor and gastrocnemius muscles may cause fracture malunion, leading to varus, flexion and internal rotation deformities of the distal fragment. Figgie et al. ${ }^{16}$ reported a progressive radiolucent lines at the bone-cement interface in 9 of the 12 femoral supracondylar TKAPF with a varus malunion.

Non-operative treatment, which includes skeletal traction, splinting, casting, and bracing, might be advantageous in patients who cannot undergo surgery.

In this cases, if a fracture reduction is considered necessary, closed reduction is followed by 4-6 weeks of cast immobilization, during which the alignment of the fracture and implant stability are regularly monitored through radiographs performed every two weeks.

In a knee with a normal component alignment and stable prosthetic fixation and minor displacement of the fracture, closed reduction and cast immobilization can provide acceptable results ${ }^{22}$.

\section{Femoral fracture}

For unstable, displaced fractures, reduction and fixation obtained with operative treatment allow early range of motion and ambulation ${ }^{14,15}$. Common surgical techniques include both external fixation and internal fixation (i.e. blade plates, condylar screws, retrograde intramedullary nails or locking plates) and revision TKA.

\section{Internal fixation with metal plates}

Some internal fixation devices, such as $95^{\circ}$ angled blade plates, dynamic condylar screws, and condylar buttress plates, do not provide stable fixation for comminuted supracondylar fractures with poor bone stock and could interfere with the femoral component or cement ${ }^{16,27,29}$. Substantial effort had been made to identify a method that ensures rigid fixation in the osteopenic bone using bone grafting or bone cement augmentation. Healy et al. treated 20 Rorabeck type II fractures using blade plates and condylar screw plates, with the addition of bone grafting in 15 knees with severe osteoporosis ${ }^{30}$. The fractures healed in all knees, although revision surgery was required due to loss of reduction in two knees ${ }^{30}$. Another critical issue of traditional plating of supracondylar fractures is the varus collapse in case of severe comminution. In these latter scenario, dual plating might be considered to prevent the secondary varization of the femur associated with single lateral traditional plating ${ }^{31}$.

Locking plates are fixed-angle devices designed to engage with the screw threads ${ }^{32}$. These plates assure a more rigid fixation compered with traditional metal plates for periarticular, comminuted, and osteoporotic fractures ${ }^{28,32}$.

A theorical disadvantage of internal fixation with plates includes the need for large surgical exposure with extensive soft

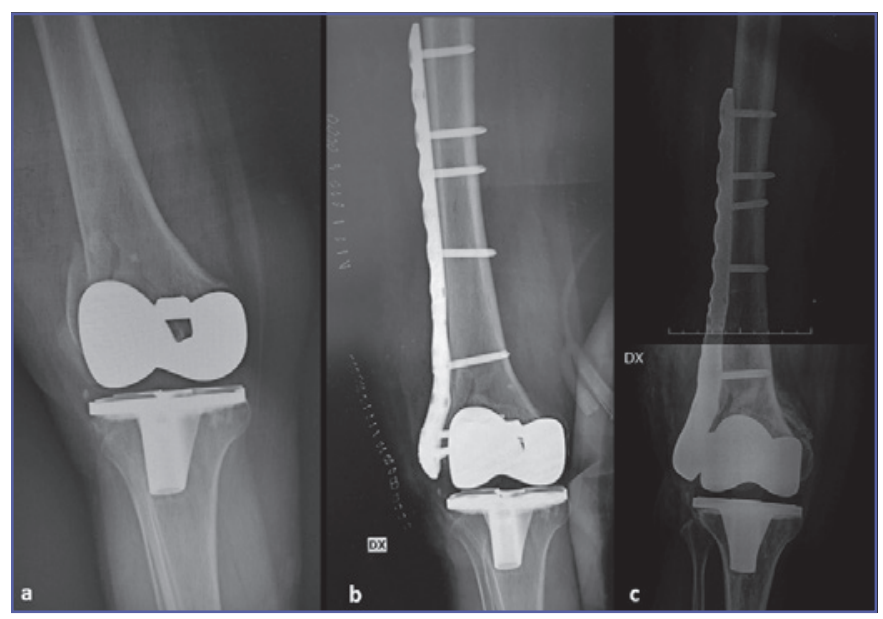

Figure 1. A Rorabeck Type I in a 74-year-oldfemale (A). The patient was treated using a locking plate through a MIPO technique (B). C) Antero-posterior X-ray at 3 months after surgery showing fracture healing. 
Table I. Classification systems of femoral and tibial TKAPF.

\begin{tabular}{|c|c|c|c|}
\hline \multicolumn{4}{|c|}{ Femur fracture } \\
\hline & Rorabeck and Taylor ${ }^{17}$ & Su et al. ${ }^{2}$ & Kim et al. ${ }^{27}$ \\
\hline Type I & $\begin{array}{l}\text { Non-displaced fracture around a well-fixed } \\
\text { prosthesis }\end{array}$ & $\begin{array}{l}\text { Fractures are proximal to the } \\
\text { femoral component }\end{array}$ & $\begin{array}{l}\text { Fracture that occurs in the } \\
\text { knee with an intact prosthesis } \\
\text { and sufficient bone stock }\end{array}$ \\
\hline Type II & $\begin{array}{l}\text { Fractures have } \geq 5 \mathrm{~mm} \text { displacement or } \geq 5^{\circ} \\
\text { angulation with the prosthesis remaining sta- } \\
\text { ble; into type IIA (non-comminuted fractures) } \\
\text { and type IIB (comminuted fractures) }\end{array}$ & $\begin{array}{l}\text { Fracture lines originate at the } \\
\text { proximal end of the femoral } \\
\text { component and partially ex- } \\
\text { tend proximally }\end{array}$ & $\begin{array}{l}\text { Revision surgery is required } \\
\text { due to unstable fixation or } \\
\text { malposition of the prosthe- } \\
\text { sis in spite of sufficient bone } \\
\text { stock and reducibility }\end{array}$ \\
\hline Type III & $\begin{array}{l}\text { Fracture is accompanied by component loos- } \\
\text { ening/instability and polyethylene wear irre- } \\
\text { spective of the displacement of fracture frag- } \\
\text { ments }\end{array}$ & $\begin{array}{l}\text { Fractures occur distal to the } \\
\text { upper edge of the femoral } \\
\text { component }\end{array}$ & $\begin{array}{l}\text { Severely comminuted facture } \\
\text { with poor bone stock }\end{array}$ \\
\hline \multicolumn{4}{|c|}{$\begin{array}{ll} & \text { Tibial fracture }\end{array}$} \\
\hline & Felix et al. ${ }^{22}$ & & \\
\hline Type I & Fractures are located at the tibial plateau & & \\
\hline Type II & $\begin{array}{l}\text { Fractures occur inferior to the tibial plateau } \\
\text { adjacent to the prosthetic stem, }\end{array}$ & & \\
\hline Type III & Fractures occur distal to the tibial stem & & \\
\hline \multirow[t]{4}{*}{ Type IV } & Fractures involve the tibial tubercle & & \\
\hline & Type A & $\begin{array}{l}\text { Fracture with a stable pros- } \\
\text { thesis on radiographs }\end{array}$ & \\
\hline & TypeB & $\begin{array}{l}\text { As fractures with radio- } \\
\text { graphic evidence of compo- } \\
\text { nent loosening }\end{array}$ & \\
\hline & Type C & Intraoperative fracture & \\
\hline
\end{tabular}

tissue damage that could lead to an increased risk of nonunion due to damage to the periosteum and blood vessels. The availability of the anatomically shaped locking plates opened to a new implantation technique known as minimally invasive percutaneous plate osteosynthesis (MIPO) (i.e.: less invasive stabilization system [LISS]). This technique allows minimizing injury to the adjacent soft tissue and periosteum, thus promoting rapid bone union with a low risk of complications compared to traditional techniques ${ }^{28,33}$. Some locking metal plates allow for closed reduction with use of percutaneous screw insertion or a retractor based on the principle of ligamentotaxis ${ }^{33}$. Kregor et al. performed LISS fixation for the treatment of supracondylar fractures and obtained bone union in 36 of 38 knees without any complications ${ }^{34}$.

However, the use of locking plates for distal femoral fractures is still debated, because of the reported healing problems and complications. In particular, a nonunion rate ranged from 0 to $19 \%$, a delayed unions ranged from 0 to $15 \%$, and an implant failures ranged from 0 to $20 \%$ were reported ${ }^{35}$. In order to improve patients outcomes, a careful preoperative planning is needed when choosing a locking plate, to identify the correct plate length, fixation working length, and screw distribution ${ }^{35}$.

\section{Retrograde intramedullary nailing}

Retrograde intramedullary nailing (RIN) is recommended for TKAPF over anterograde nails, also considering the difficulties in obtaining the distal locking of the latter ${ }^{36}$. Compared to conventional plate fixation, RIN is associated with less soft tissue damage and blood loss. In addition, the preservation of periosteal blood supply and fracture hematoma promotes bone union.

Currently used interlocking intramedullary nailing takes advantage of interlocking screws that allow higher resistance to axial compression and torsional forces. RIN of Rorabeck type II supracondylar femoral fractures yields high union rates and excellent functional outcomes ${ }^{37}$. RIN should be long enough 


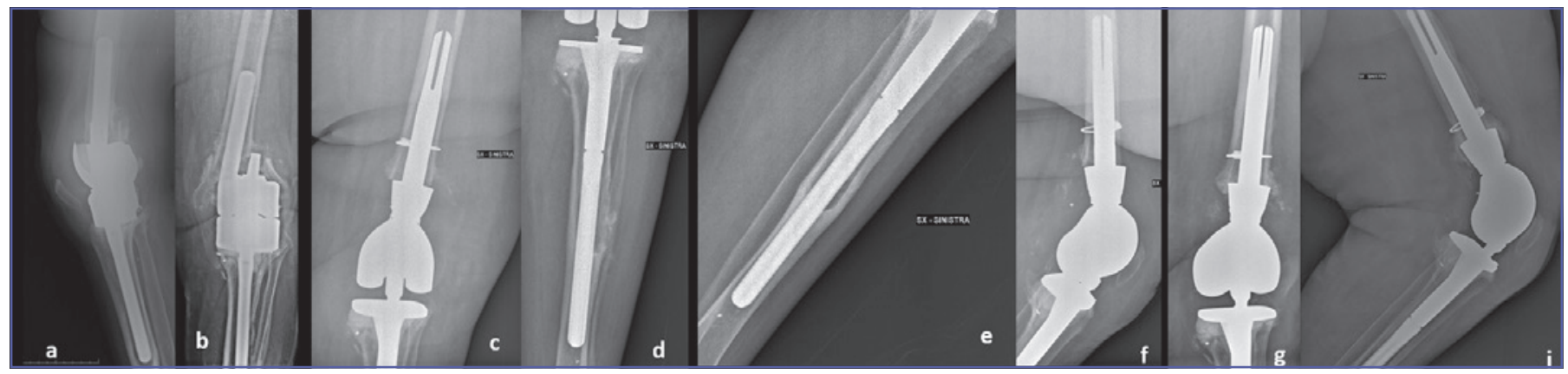

Figure 2. A,B) A TKAPF around a revision arthroplasthy occurred in a 71-year-old female involving both the femur (Roraback type 3) and the tibia (Friser type 2). Considering the poor bone stock and the patient's age, a mega-prosthesis was used. (C,D,E,F). In G and H, antero-posterior and lateral x-ray at 1 year of follow-up. The patient was able to walk without aid.

to reach the level of the lesser trochanter, considering that the engagement of the isthmus prevents a windshield wiper effect and improves stability ${ }^{38}$. Hyperextension of the femoral component may occur in the sagittal plane because reaming and insertion are performed with the knee in flexion position and can be more evident if the insertion site is posterior to the intercondylar notch. According to Pelfort et al., hyperextension of the femoral component does not significantly affect stability of the prosthesis, bone union, or knee joint function ${ }^{39}$. Valgus malalignment of the distal fragment in the coronal plane is often encountered. To avoid this, it is recommended to use a blocking screw as a guide for proper insertion of the intramedullary nail ${ }^{40}$.

Before performing a RIN osteosynthesis, the surgeon must be aware of the shape of the femoral component of the impanted TKA, to be sure that the distal entry point between the condyles is 'opened'. In fact, TKA with a box (e.g. posteriorly stabilized) or with a stem cover the RIN entry point. In this case, a plate might be used ${ }^{36}$.

Contraindications to intramedullary nailing include patellar baja, joint ankylosis precluding intramedullary nail insertion, $<11 \mathrm{~mm}$ intercondylar distance or narrow medullary cavity, preexisting intramedullary stem in the proximal femur from previous total hip arthroplasty, severe comminution or extremely distal fracture precluding stable internal fixation and unstable TKA prosthesis ${ }^{38-40}$.

\section{Revision total knee arthroplasty}

Revision TKA (RTKA) should be considered in case of femoral component instability (regardless of the degree of fracture comminution and displacement) ${ }^{14,15,29,41}$, severe comminution or fracture periarticualar extension that precluding internal fixation, failure of previous treatments, and severe malalignment of the TKA ${ }^{14,15,19,41}$.

During revision TKA, a long-stemmed femoral component is inserted through the fracture site into the proximal femur over- coming the fracture site ${ }^{15,16,19,29}$. Although cemented femoral components are commonly used, if fracture stability cannot be obtained using only the long stem, strut allograft or cerclage wiring should be used to improve stability of both the fracture and the femoral component ${ }^{16,29}$. If nonunion occurs due to the lack of bone stock, distal femoral replacement using a megaprosthesis may be considered as a limb salvage procedure to preserve minimum knee function and maintain the length of the leg ${ }^{42}$. Freedman et al. reported that distal femoral replacement performed using a tumor megaprosthesis due to nonunion and comminution following internal fixation of periprosthetic supracondylar fractures resulted in early ambulation and $100^{\circ}$ of range of motion in 4 of 5 knees ${ }^{42}$.

A high complication rate for distal femur megaprosthesis has been reported. Mortazavi et al. observed an overall complication rate of $50 \%$ and a reoperation rate of $22.3 \%{ }^{43}$. The complications included infection, fractures around or above the femoral prosthesis, and femoral component loosening ${ }^{11}$. Berend and Lombardi reported a complication rate of $18 \%$, a reoperation rate of $13.5 \%$, and an infection rate of $8 \%{ }^{44}$. In contrast, Saidi et al reported no complications and Girgis et al. a complication rate of $14.2 \%{ }^{45,46}$. Of note, the reported mortality rate of distal femur periprosthetic fractures treated with revision arthroplasthy is high. Hoellwarth et al. reported a $4 \%$ mortality rate at 90 days and $10 \%$ mortality rate at 1 year ${ }^{47}$.

\section{Tibial fracture}

The treatment of severely displaced, unstable periprosthetic tibial fracture can be perfomed using open reduction and internal fixation. Plates are commonly used for internal fixation because the preexisting tibial component precludes insertion of intramedullary nails ${ }^{6,22}$. Even in a knee with poor bone stock, locking plates with several locking screws inserted around the tibial stem allow rigid fixation. In cases of intraoperative fractures, treatment decisions are based on the status and site of the 


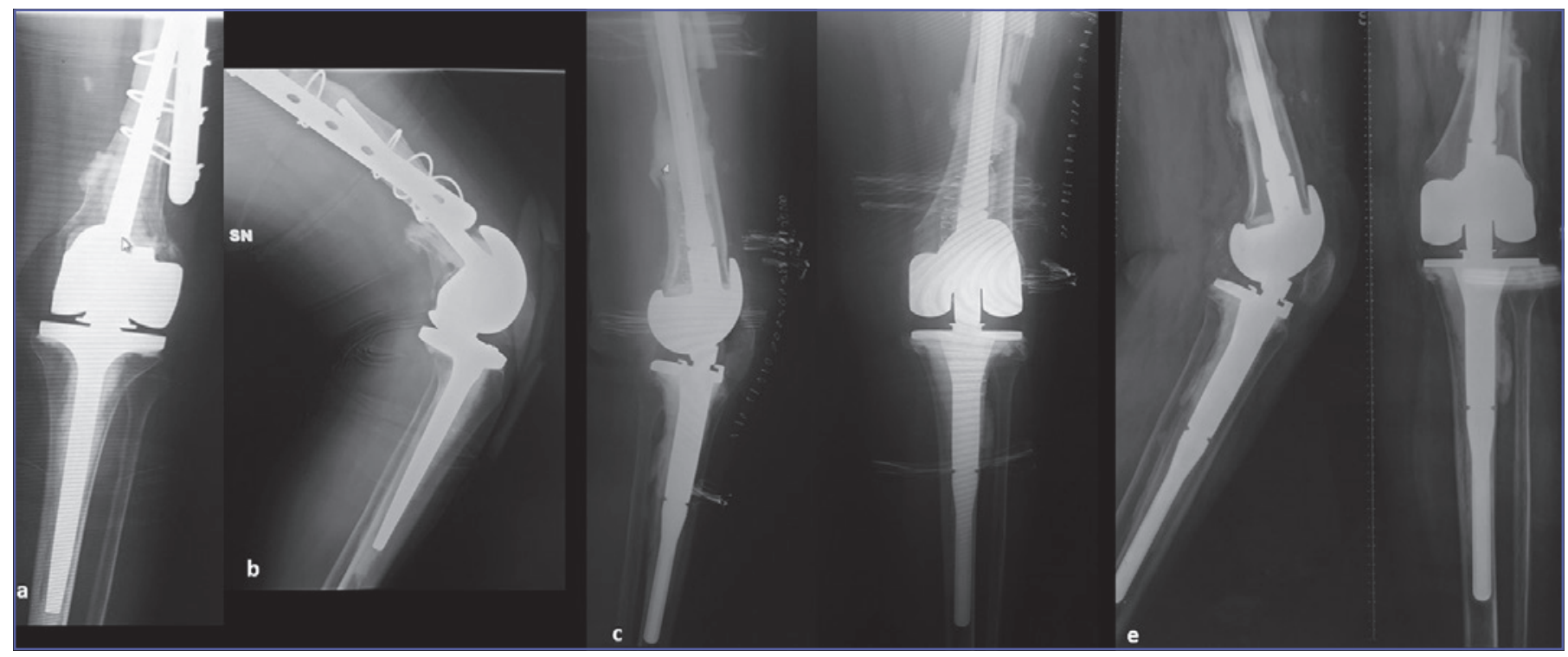

Figure 3. A,B) A 65-year-old female who developed a nonunion after a TKAPF treated with with plate and screws. Note the poor bone stock in the distal femur and fracture malalignment. The patient was treated using an allograft-prosthesis composite (C). In D, antero-posterior and lateral x-rays at 1 year after the surgery. Note the allograft osteointegration.

fracture. For unstable type IC fractures, screw fixation of bone fragments is followed by insertion of a long-stemmed tibial component through the fracture site to the tibial medullary cavity. Type IIC fractures are treated using a long-stemmed tibial component and bone graft for bone defects at the fracture site. Type IIIC fractures are managed with either internal fixation or conservative treatment based on the fracture site and pattern ${ }^{6}$. Type IV fractures that involve the tibial tubercle should be treated with care to avoid disruption of the extensor mechanism. Felix et al. ${ }^{22}$ obtained bone union without any complication in 2 type IVA fractures after cast immobilization with knee extension in one case and screw fixation in the other case. Hanssen and Stuart suggested the use of polypropylene mesh tape or semitendinosus rerouting for fixation of tibial bone fragments in cases of type IV fractures ${ }^{48}$.

The thin layer of soft tissue overlying the tibia predisposes to soft-tissue complications. Ideally, fixation of these fractures is achieved via a limited open approach proximally, that facilitates fracture reduction, and a MIPO for the insertion of the plate to preserve the local blood supply of the limited soft tissue ${ }^{36}$.

Platzer et al. reviewed outcomes of 41 periprosthetic fractures after TKA ${ }^{49}$. Of these 41 fractures, 4 were in the tibia (1 Felix type IA, 2 Felix type IIA, 1 Felix type IVA). The Felix type IA fracture was managed nonsurgically, and the other three were managed with plate fixation ${ }^{49}$. Nonunion developed in one of the three proximal tibial fractures managed with plate fixation. The other three fractures healed successfully within 6 months after intervention ${ }^{49}$.
Haller et al. suggested a technique for implantation of an IM nail for management of four Felix type IIIA periprosthetic tibial fractures ${ }^{50}$. Their proposed technique included the use of a more distal transpatellar entry point, hand reaming of the proximal tibia part adjacent to the implant, the use of a suction tip to navigate the guidewire past the posterior cortex, the insertion of a nail with a diameter of $9 \mathrm{~mm}$, and bending the nail with a bending press. At final follow-up (mean, 14.3 months), all four fractures had achieved union and all patients had returned to baseline function ${ }^{50}$.

If the tibial component is unstable, revision TKA should be considered ${ }^{18,21,22}$. In revision TKA, the tibial component fixation should use a longer stem, in order to overcome the fracture site of the proximal tibia ${ }^{14,21,22}$. After tibial component fixation, additional internal fixation may be required for the remaining unstable bone fragments. Any bone defects in the proximal tibia should be treated using metal augmentation. These latter units with thick polyethylene insertion can be effective for treating $\leq 5 \mathrm{~cm}$ deep bone defects. More severe bone defects or comminuted fractures should be managed using either strut allograft or tumor megaprosthesis ${ }^{48}$.

Subtype B periprosthetic tibial fractures should be managed with a revision TKA with a long-stem tibial component ${ }^{51,52}$. Abbas and Morgan-Jones reviewed revision TKA in six patients with nonunion and malunion ${ }^{52}$. At final follow-up, all patients were ambulatory and exhibited significant improvement in mean range of motion and Oxford Knee Score ${ }^{52}$.

Bone allograft was a successful augmentation in the reconstruction of periprosthetic tibial fractures with a massive bone defect ${ }^{53}$. 
Ghazavi et al. used a long-stem tibial component with bone allograft in three periprosthetic tibial fractures with bone defects over $3 \mathrm{~cm}$ in length ${ }^{54}$. At a mean follow-up of 50 months (range, 24 to 132 months), the results were successful in all three cases in terms of bone union at the allograft-host junction and functional score ${ }^{54}$. Megaprostheses are rarely indicated in the management of periprosthetic tibial fractures because of the challenge of reestablishing the insertion of the extensor mechanism ${ }^{55}$. Type IB fractures with severe comminution or major cortical destruction secondary to osteolysis are the only indication for reconstruction with megaprostheses ${ }^{22,55}$. Windhager et al. reviewed the use of megaprostheses in 11 patients with periprosthetic fractures of the knee ${ }^{55}$. Only one of these patients had a periprosthetic tibial fracture (type IB) ${ }^{55}$. After 62-months of follow-up, the patient had no pain and a Medical Outcomes Study 12-Item Short Form score of 42. In their review of the literature, Windhager et al. found that revision rates associated with megaprostheses ranged from zero to $55 \%$. Most revisions were performed because of mechanical factors or infection ${ }^{55}$.

\section{Conclusions}

TKPFA are a challenge for the orthopedic surgeon. Undisplaced fractures with well fixed implants can be treated with plate fixation or intramedullary nailing, when possible (i.e. cruciate sparing TKA or Felix type III tibial fractures).

In case of poor bone stock, comminution, severe osteoporosis, or prosthesis loosening, a revision arthroplasty is required, also using mega-prosthesis or composite implant.

Considering the high rate of complications and extreme variability of the surgical scenario, the orthopedic surgeon should be able to use all available fixation tecniques and perform a revision arthroplasty. Therefore, a high specialized surgical team and comprehensive equipment is needed to improve patient outcames.

\section{References}

1 Della Rocca GJ, Leung KS, Pape H-C. Periprosthetic fractures: epidemiology and future projections. J Orthop Trauma 2011;25(Suppl 2):S66-70.

2 Su ET, DeWal H, Di Cesare PE. Periprosthetic femoral fractures above total knee replacements. J Am Acad Orthop Surg 2004;12:12-20.

3 Agarwal S, Sharma RK, Jain JK. Periprosthetic fractures after total knee arthroplasty. J Orthop Surg Hong Kong 2014;22:24-9.

4 Ritter MA, Thong AE, Keating EM, et al. The effect of femoral notching during total knee arthroplasty on the prevalence of postoperative femoral fractures and on clinical outcome. J Bone Joint Surg Am 2005;87:2411-4.

5 Burnett RS, Bourne RB. Periprosthetic fractures of the tibia and patella in total knee arthroplasty. Instr Course Lect 2004;53:217-35.

6 Alden KJ, Duncan WH, Trousdale RT, et al. Intraoperative fracture during primary total knee arthroplasty. Clin Orthop 2010;468:90-5.

7 Yoo JD, Kim NK. Periprosthetic fractures following total knee arthroplasty. Knee Surg Relat Res 2015;27:1-9.
8 Diehl P, Burgkart R, Klier T, et al. Periprothetische frakturen nach knietotalendoprothetik. Orthop 2006;35:961-74.

9 Erhardt JB, Kuster MS. Periprosthetic fractures of the knee joint. Orthopade 2010;39:97-108.

10 Drew JM, Griffin WL, Odum SM, et al. Survivorship after periprosthetic femur fracture: factors affecting outcome. J Arthroplasty 2016;31:1283-8.

11 Jennison T, Yarlagadda R. Mortality in patients sustaining a periprosthetic fracture following a previous extracapsular hip fracture fixation. Injury 2018;49:702-4.

12 Fakler JKM, Pönick C, Edel M, et al. A new classification of TKA periprosthetic femur fractures considering the implant type. BMC Musculoskelet Disord 2017;18:490.

13 Herrera DA, Kregor PJ, Cole PA, et al. Treatment of acute distal femur fractures above a total knee arthroplasty: systematic review of 415 cases (1981-2006). Acta Orthop 2008;79:22-7.

14 Dennis DA. Periprosthetic fractures following total knee arthroplasty. Instr Course Lect 2001;50:379-89.

15 Chen F, Mont MA, Bachner RS. Management of ipsilateral supracondylar femur fractures following total knee arthroplasty. J Arthroplasty 1994;9:521-6.

16 Figgie MP, Goldberg VM, Figgie HE, et al. The results of treatment of supracondylar fracture above total knee arthroplasty. J Arthroplasty 1990;5:267-76.

17 Rorabeck CH, Taylor JW. Periprosthetic fractures of the femur complicating total knee arthroplasty. Orthop Clin North Am 1999;30:265-77.

18 Scott WN, Diduch DR, Iorio R, et al. Insall \& Scott surgery of the knee, 2018 (https://www.clinicalkey.com/dura/browse/bookChapter/3-s2.0-C20141045747).

19 Culp RW, Schmidt RG, Hanks G, et al. Supracondylar fracture of the femur following prosthetic knee arthroplasty. Clin Orthop 1987:212-22.

20 Ritter MA, Faris PM, Keating EM. Anterior femoral notching and ipsilateral supracondylar femur fracture in total knee arthroplasty. J Arthroplasty 1988;3:185-7.

21 Rand JA, Coventry MB. Stress fractures after total knee arthroplasty. J Bone Joint Surg Am 1980;62:226-33.

22 Felix NA, Stuart MJ, Hanssen AD. Periprosthetic fractures of the tibia associated with total knee arthroplasty. Clin Orthop 1997;345:113-24.

23 Ritter MA, Carr K, Keating EM, et al. Tibial shaft fracture following tibial tubercle osteotomy. J Arthroplasty 1996;11:117-9.

24 Lotke PA, Ecker ML. Influence of positioning of prosthesis in total knee replacement. J Bone Joint Surg Am 1977;59:77-9.

25 Backstein D, Safir O, Gross A. Periprosthetic fractures of the knee. J Arthroplasty 2007;22(4 Suppl 1):45-9.

26 Vasso M, Braile A, Ascione F, et al. Two-stage reimplantation in periprosthetic knee infection. Eur Rev Med Pharmacol Sci 2019;23(Suppl 2):51-8.

27 Ruchholtz S, Tomás J, Gebhard F, et al. Periprosthetic fractures around the knee - the best way of treatment. Eur Orthop Traumatol 2013;4:93-102.

28 Kim K-I, Egol KA, Hozack WJ, et al. Periprosthetic fractures after total knee arthroplasties. Clin Orthop 2006;446:167-75.

29 DiGioia AM, Rubash HE. Periprosthetic fractures of the femur after total knee arthroplasty. A literature review and treatment algorithm. Clin Orthop 1991;271:135-42.

30 Cordeiro EN, Costa RC, Carazzato JG, et al. Periprosthetic 
fractures in patients with total knee arthroplasties. Clin Orthop 1990;252:182-9.

31 Healy WL, Siliski JM, Incavo SJ. Operative treatment of distal femoral fractures proximal to total knee replacements. J Bone Joint Surg Am 1993;75:27-34.

32 Gurava Reddy V, Krishna Mootha A, Chiranjeevi T, et al. Bilateral symmetrical periprosthetic (mirror) fractures of knee fixed with dual plating technique. Int J Surg Case Rep 2011;2:175-7.

33 Frigg R, Appenzeller A, Christensen R, et al. The development of the distal femur Less Invasive Stabilization System (LISS). Injury 2001;32(Suppl 3):SC24-31.

34 Zlowodzki M, Williamson S, Cole PA, et al. Biomechanical evaluation of the less invasive stabilization system, angled blade plate, and retrograde intramedullary nail for the internal fixation of distal femur fractures. J Orthop Trauma 2004;18:494-502.

35 Kregor PJ, Hughes JL, Cole PA. Fixation of distal femoral fractures above total knee arthroplasty utilizing the Less Invasive Stabilization System (L.I.S.S.). Injury 2001;32(Suppl 3):SC64-75.

36 Toro G, Calabrò G, Toro A, et al. Locking plate fixation of distal femoral fractures is a challenging technique: a retrospective review. Clin Cases Miner Bone Metab Off J Ital Soc Osteoporos Miner Metab Skelet Dis 2015;12(Suppl 1):55-8.

37 Murrell GA, Nunley JA. Interlocked supracondylar intramedullary nails for supracondylar fractures after total knee arthroplasty. A new treatment method. J Arthroplasty 1995;10:37-42.

38 Lee S-S, Lim S-J, Moon Y-W, et al. Outcomes of long retrograde intramedullary nailing for periprosthetic supracondylar femoral fractures following total knee arthroplasty. Arch Orthop Trauma Surg 2014;134:47-52.

39 Pelfort X, Torres-Claramunt R, Hinarejos P, et al. Extension malunion of the femoral component after retrograde nailing: no sequelae at 6 years. J Orthop Trauma 2013;27:158-61.

40 Jabczenski FF, Crawford M. Retrograde intramedullary nailing of supracondylar femur fractures above total knee arthroplasty. A preliminary report of four cases. J Arthroplasty 1995;10:95-101.

41 Engh GA, Ammeen DJ. Periprosthetic fractures adjacent to total knee implants: treatment and clinical results. Instr Course Lect 1998;47:437-48.

42 Freedman EL, Hak DJ, Johnson EE, et al. Total knee replacement including a modular distal femoral component in elderly patients with acute fracture or nonunion. J Orthop Trauma 1995;9:231-7.

43 Mortazavi SMJ, Kurd MF, Bender B, et al. Distal femoral arthro- plasty for the treatment of periprosthetic fractures after total knee arthroplasty. J Arthroplasty 2010;25:775-80.

44 Berend KR, Lombardi AV. Distal femoral replacement in nontumor cases with severe bone loss and instability. Clin Orthop 2009;467:485-92.

45 Saidi K, Ben-Lulu O, Tsuji M, et al. Supracondylar periprosthetic fractures of the knee in the elderly patients: a comparison of treatment using allograft-implant composites, standard revision components, distal femoral replacement prosthesis. J Arthroplasty $2014 ; 29: 110-4$.

46 Girgis E, McAllen C, Keenan J. Revision knee arthroplasty using a distal femoral replacement prosthesis for periprosthetic fractures in elderly patients. Eur J Orthop Surg Traumatol Orthop Traumatol 2018;28:95-102.

47 Hoellwarth JS, Fourman MS, Crossett L, et al. Equivalent mortality and complication rates following periprosthetic distal femur fractures managed with either lateral locked plating or a distal femoral replacement. Injury 2018;49:392-7.

48 Hanssen AD, Stuart MJ. Treatment of periprosthetic tibial fractures. Clin Orthop 2000;380:91-8.

49 Platzer P, Schuster R, Aldrian S, et al. Management and outcome of periprosthetic fractures after total knee arthroplasty. J Trauma 2010;68:1464-70.

50 Haller JM, Kubiak EN, Spiguel A, et al. Intramedullary nailing of tibial shaft fractures distal to total knee arthroplasty. J Orthop Trauma 2014;28:e296-300.

51 Ebraheim NA, Ray JR, Wandtke ME, et al. Systematic review of periprosthetic tibia fracture after total knee arthroplasties. World J Orthop 2015;6:649-54.

52 Abbas AMI, Morgan-Jones RL. Revision total knee arthroplasty for failure of primary treatment of periprosthetic knee fractures. $J$ Arthroplasty 2014;29:1996-2001.

53 Born CT, Gil JA, Johnson JP. Periprosthetic tibial fractures. J Am Acad Orthop Surg 2018;26:e167-72.

54 Ghazavi MT, Stockley I, Yee G, et al. Reconstruction of massive bone defects with allograft in revision total knee arthroplasty. J Bone Joint Surg Am 1997;79:17-25.

55 Windhager R, Schreiner M, Staats K, et al. Megaprostheses in the treatment of periprosthetic fractures of the knee joint: indication, technique, results and review of literature. Int Orthop 2016;40:935-43. 